\title{
Optimization of Media and Feeding Strategy for Improved Capsular Polysaccharide Yield for Neisseria meningitidis W-135
}

\author{
Sujitha Valiya Kambrath ${ }^{1}$, Srinivas R Peddi Reddy ${ }^{2}$, \\ Sambhaji S Pisal ${ }^{3}$, Rajeev M Dhere ${ }^{4}$ \\ ${ }^{1,2,3,4}$ Serum Institute of India Pvt. Ltd., 212/2, Off Soli Poonawalla Road, Hadapsar, Pune, Maharashtra 411028, \\ India.
}

\begin{abstract}
Meningococcal serogroup W-135 (MenW-135) has turned out to be the reason for recent outbreak of meningitis in the sub-Saharan regions of Africa including Cameroon, Chad, Gambia, Burkina Faso, and other countries. The capsular polysaccharide (PS) of Neisseria meningitidis serogroups A, C, X, Y, and W-135 are excellent vaccine targets against meningitis caused by this bacterium. This study promotes a novel feed solution including amino acids, vitamins, and glucose along with an optimal fermentation medium; and feeding strategy to cultivate high yield polysaccharide at harvest level. The study is based on the hypothesis that glucose is one of the major growth determining factors with the combinations of nitrogen sources. In this study, fed-batch cultivation was performed in a $2 \mathrm{~L}$ fermenter, maintaining the following conditions: (i) Temperature $=37^{\circ} \mathrm{C}$ (ii) $\mathrm{pH}=7.0$ (iii) Agitation frequency in the range 150 rotations per minute (rpm) to $500 \mathrm{rpm}$, and (iv) Dissolved oxygen (DO) $20 \%-25 \%$. The bacterial growth and polysaccharide production were found to be enhanced when the feed flow was increased periodically from late lag phase to early decline phase. The polysaccharide production was found to be maximum in the early decline phase of the bacterial growth. The said method produced polysaccharide of about $1000 \mathrm{mg} / \mathrm{L}$, which is twice the reported method. There is limited research information available on fed-batch cultivation and feeding strategy for growing Neisseria meningitidis W-135. The major findings of this study can provide significant contribution in the field of capsular polysaccharide production from which MenW polysaccharide vaccines are manufactured.
\end{abstract}

Keywords: Neisseria meningitidis W-135, Capsular polysaccharide, Glucose feed, Fed-batch cultivation, Fermentation parameters

Date of Submission: 01 February 2017

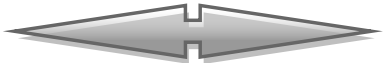

Date of Accepted: 13 February 2017

\section{INTRODUCTION}

Meningococcal disease or meningitis is a major cause of death and morbidity throughout the world. Meningitis is responsible for the inflammation of meninges, the protective membranes that covers the brain and spinal cord. Of thirteen clinically significant serogroups that depend on the antigenic structure of their polysaccharide capsule, serogroups A, B, C, X, Y, and $\mathrm{W}-135$ are the major pathogenic strains. Neisseria meningitidis $\mathrm{W}-135$ is the reason for the most recent outbreak of meningitis in the sub-Saharan regions of Africa [1-3]. MenW-135 polysaccharide capsule is a hetero polymer composed of $\alpha-2$, 6-linked sialic acid and galactose, that is, -4$)-\mathrm{NeuAc}-\alpha(2,6)-\mathrm{Gal}-\alpha(1-$, in which the hydroxyl group of sialic acid residue is the site (at C7 and C-9 positions) of O-acetylation. O-acetylation enhances the immunogenicity of the antigen [4-6]. Neisseria meningitidis is a human pathogen best known for its role in meningitis and other forms of meningococcal diseases such as meningococcal septicemia [7, 8]. Meningococcal disease is serious in nature and if not treated in time, it can progress to death over a matter of hours, in which the mortality reaches $100 \%$ [9-11].

Many attempts have been started from the beginning of the $20^{\text {th }}$ century to control meningococcal disease with the administration of vaccines developed from the whole dead cells but they have been unsuccessful. Hence, isolate structures were studied for developing vaccines in which surface structures and bacterium extracellular products were most relevant [9]. The unique structure of the extracellular polysaccharide makes it a good target for vaccine design [5]. Because the bacterial capsular polysaccharides and proteins are the vaccine targets related to bacterial structure, the bacterial growth and nutrient consumption are major factors to be investigated. Although meningococcal vaccines are available in the market with different names such as Menactra for ACYW-DT, Menveo for ACYW-CRM197, and Nimenrix for ACYW-TT; they are costly due to low polysaccharide yield at fermentation harvest level. This makes the vaccines unaffordable to people of developing countries. 
Limited information is available about significance of glucose feeding along with amino acid mixture on growth of Neisseria meningitidis W-135 for improved yield of capsular polysaccharide. Major findings of this study can provide significant contribution to fed-batch mode cultivation of Neisseria meningitidis W-135. This study was performed with four experimental batches of Neisseria meningitidis W-135. The feed was supplemented periodically to enhance the growth. Polysaccharide was extracted and purified from the harvested culture by various precipitation methods and tangential flow filtration (TFF). Then the sample for polysaccharide concentration and other WHO specified parameters were analyzed. The outcome of this study can be extrapolated for the production of polysaccharide for the development of efficient and cost effective vaccine for Neisseria meningitidis $\mathrm{W}-135$.

\subsection{Cultivation media and feed media}

\section{MATERIALS AND METHODS}

Fermentation media $(\mathrm{g} / \mathrm{L})$ :

Glucose - 10.0; Sodium Chloride $(\mathrm{NaCl})$ - 6.0; Dipotasium sulphate $\left(\mathrm{K}_{2} \mathrm{SO}_{4}\right)$ - 1.0; Di potassium hydrogen phosphate $\left(\mathrm{K}_{2} \mathrm{HPO}_{4}\right)$ - 4.0; Monosodium glutamate - 10.0; Arginine - 0.75; Serine - 0.75; Thiamine - 0.05; Cysteine - 0.4; Magnesium Chloride $\left(\mathrm{MgCl}_{2}\right)$ - 0.3; Calcium Chloride $\left(\mathrm{CaCl}_{2}\right)$ - 0.02; Iron sulphate $\left(\mathrm{FeSO}_{4}\right)$ 0.01; Yeast extract - 3.0; Casamino acid - 5.0; Soya - 3.0; Ammonium Chloride $\left(\mathrm{NH}_{4} \mathrm{Cl}\right)$ - 0.25

Feed media $(\mathrm{g} / \mathrm{L})$ :

Glucose - 100, Monosodium glutamate - 75, Arginine - 2, Serine - 2, $\mathrm{MgCl}_{2}-0.8 ; \mathrm{CaCl}_{2}-0.1 ;$ Soya $-2 ; \mathrm{NH}_{4} \mathrm{Cl}-$ 0.4 ; ready mixture of amino acids, vitamins and glucose -3.0 to $5.0 \%$. The ready mix is a mixture of amino acids, vitamins, and glucose. Here commercially available product named Cell Boost ${ }^{\mathrm{TM}}$ was used as ready mix.

- Fermenter (2L), New Brunswick, Bioflow-Celligen 115, New Jersey, N, USA

- Peristaltic pump (Master Flex, Cole Parmer, IL, USA)

- UV-Vis Spectrophotometer (Shimadzu)

- Biochemical analyzer (Xylem)

- Microplate reader (BioTek)

- HPLC-SEC (Waters corp., Milford, MA, USA)

\subsection{Cultivation method}

Fed-batch fermentation was performed to cultivate Neisseria meningitidis W-135. Single vial with 1.0 OD was taken from working cell bank and inoculated into $40 \mathrm{ml}$ of growth media with $\mathrm{pH} 7.0$ and allowed to grow by shake flask method at $250 \mathrm{rpm}, 37^{\circ} \mathrm{C}$. The $40 \mathrm{ml}$ grown culture with OD 1.2 at $590 \mathrm{~nm}$ was inoculated into $760 \mathrm{ml}$ of fermentation media so that the total volume was $800 \mathrm{ml}$ and initial OD after inoculation was $0.05-0.08$. The media in the $2 \mathrm{~L}$ fermentation vessel was inoculated from the shake flask grown culture such that the initial OD after inoculation was $0.08-0.1$. $\mathrm{pH}$ was adjusted to 7.00 using $0.25 \mathrm{M}$ alkali treatment during the course of fermentation. The fermentation parameters that were optimized for bacterial growth were: Temperature $=37^{\circ} \mathrm{C}$, Agitation range $=150 \mathrm{rpm}$ to $500 \mathrm{rpm}$, Dissolved oxygen $=20 \%-25 \%$. During the fedbatch run, the feed was fed using the peristaltic pump from late lag phase (that is, $4^{\text {th }} / 5^{\text {th }}$ hour of the culture age). The feed flow rate was maintained from lesser volume in the lag phase to gradual increase to the early decline phase, according to the nutrient requirement (as per cell density measurement at $\mathrm{OD}_{590}$ ). At the interval of 1 hour, the growth at $\mathrm{OD}_{590}$ and glucose concentration in the media by biochemical analyzer was checked and recorded. The liquid culture was grown until the decline phase (that is, 16-18 hrs of culture age) and inactivated by adding $1.5 \%-2.0 \%(\mathrm{v} / \mathrm{v})$ formaldehyde and was kept for $2 \mathrm{hrs}$ at $37^{\circ} \mathrm{C}$ for complete inactivation. The culture was subjected to centrifugation at $8000 \mathrm{rpm}$ for 60 minutes at $2^{\circ}-8^{\circ} \mathrm{C}$ in which the cells got settled and supernatant was collected containing the capsular polysaccharide. The supernatant was filtered through $0.2 \mu \mathrm{m}$ membrane filter, followed by diafiltration and concentration by tangential flow filtration (TFF) using $100 \mathrm{kDa}$ cassette.

Experiment to determine the hourly polysaccharide production was performed to optimize the harvest hour. Culture was withdrawn (minimum volume) through the sampling port from the running batch and inactivated, centrifuged and filtered. The filtered sample was subjected to TFF using $100 \mathrm{kd}$ cassette and the concentrated sample was analyzed for polysaccharide content and impurity present.

\subsection{Isolation of MenW-135 polysaccharide}

Isolation and purification of polysaccharide from the crude harvest was done by various precipitation methods [12]. 


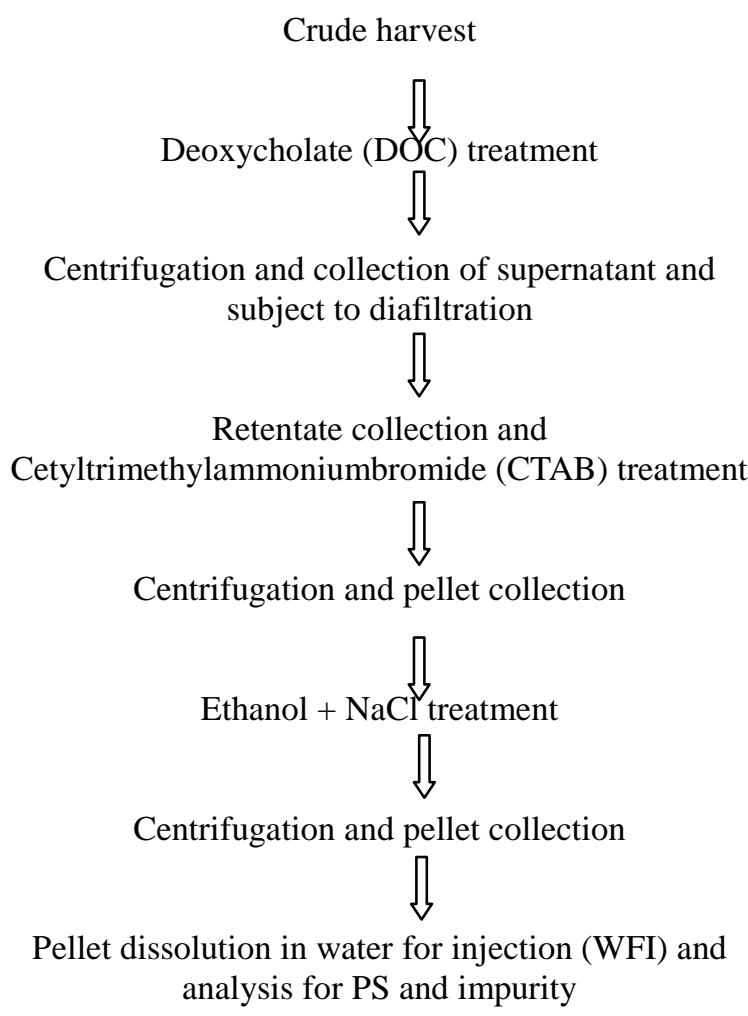

\subsection{Characterization of MenW-135 polysaccharide}

\subsubsection{Polysaccharide content}

The estimation of produced MenW-135 polysaccharide concentration in the harvested crude and purified sample was estimated by Resorcinol-HCl method [13].

\subsubsection{Protein and nucleic acid impurity}

The total protein was determined by Lowry method [14]. The nucleic acid content in MenW-135 sample was determined by ultraviolet (UV) spectroscopy at $260 \mathrm{~nm}$ assuming that a nucleic acid concentration of $50 \mu \mathrm{g} / \mathrm{ml}$ gives an optical density, $\mathrm{OD}_{260}=1$.

\subsubsection{Endotoxin content}

The Endotoxin content was determined by Kinetic Turbidometric Limulus amoebocyte lysate (Charles River Laboratories, USA) with a microplate reader (BioTek) using Endo-Scan-V ${ }^{\mathrm{TM}}$ software (Charles River Laboratories, USA).

\subsubsection{O-Acetyl content}

The O-acetyl content in the produced polysaccharide was quantified by Hestrin method [15].

2.4.5. NMR spectroscopy

The structure of MenW polysaccharide was determined by NMR spectroscopy using Bruker Advance III 400 NMR spectrometer.

\section{RESULTS}

The current study was performed with different experimental batches of Neisseria meningitidis W-135. The effect of high glucose concentration along with amino acid mixture present in the cultivation media on bacterial growth in the course of fermentation has been shown in Fig-2 and Fig-4.

The study shows that the bacterial growth greatly depends on glucose concentration and amino acid mixture along with other nutrients in the cultivation media. In Experiment 1, feed flow rate was constant. In Experiments 2, 3, and 4, the feed flow rate increased periodically according to the glucose consumption profile determined by the Biochemical analyzer, (for example, glucose in the media was maintained constant).

Different flow rates were followed in each experiment. The periodic increase in the rate of feed optimized was $90 \mathrm{ml}, 120 \mathrm{ml}, 150 \mathrm{ml}$, and $180 \mathrm{ml}$ respectively in the media after feeding from late lag phase to early decline phase.

Fig-1 shows the bacterial growth rate was better in Experiments 2, 3, and 4 compared to Experiment 1 which indicates that maintained glucose feeding enhanced bacterial growth.

Fig-2 shows, in Experiment 1, the media glucose approached zero that indicates the bacterial growth must have proceeded through nutrient starvation, whereas in Experiments 3 and 4, media glucose level did not 
approach zero and maintained a concentration of $0.4-0.5 \mathrm{~g} / \mathrm{L}$ that showed better growth profile. Growth rate was less comparatively in Experiment 2 due to less feed flow rate and media glucose was about $0.2-0.3 \mathrm{~g} / \mathrm{L}$.

Fig-1 and Fig-2 conclude that feed flow rate and glucose consumption affect bacterial growth significantly. Batches in which flow rate was maintained (Experiments 2, 3, and 4), a rhythmic increase in glucose consumption (that is, gradual decrease and maintenance of glucose present in the media) was observed, whereas in Experiment 1 in which the feed flow rate was constant, the bacterial growth diminished compared to other experiments.

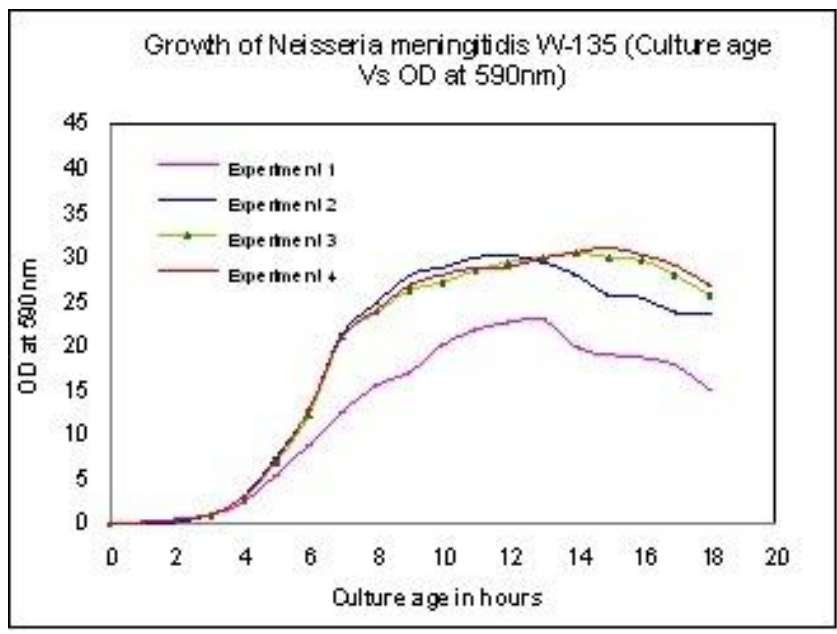

Figure 1: Bacterial growth curve (OD) / hour of Neisseria meningitidis W-135 during the fed-batch cultivation

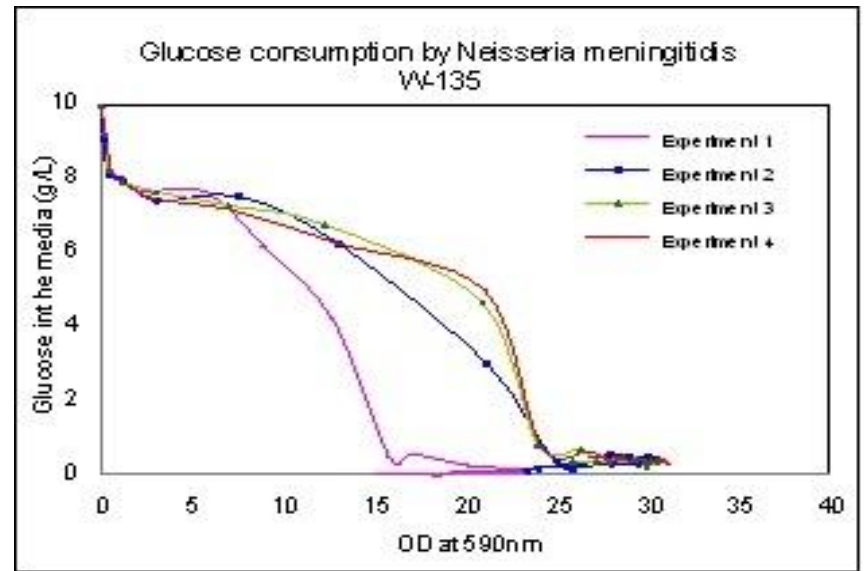

Figure 2: Glucose consumption vs bacterial growth / hour by Neisseria meningitidis W-135 during the fedbatch mode cultivation

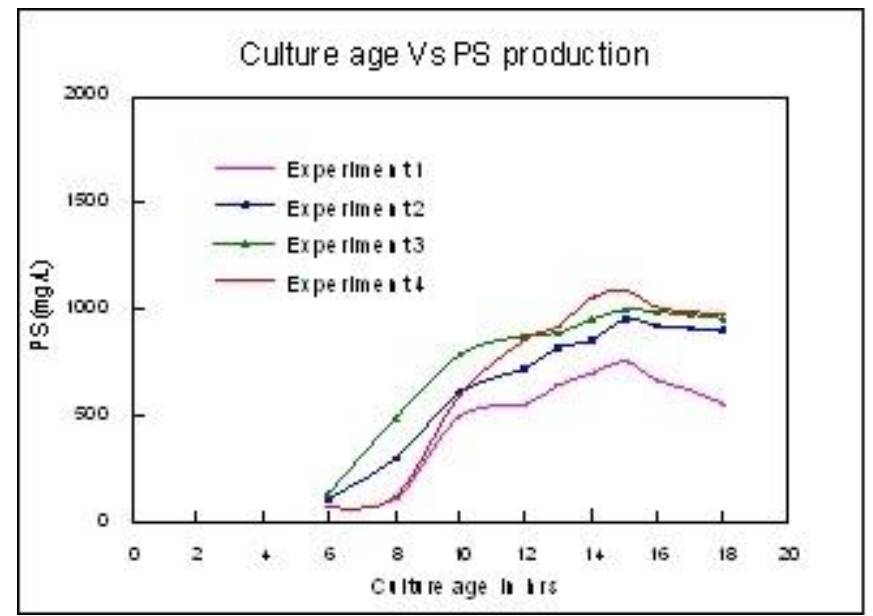

Figure 3: Polysaccharide production with culture age 
It was found that polysaccharide production is higher in the early decline phase of bacterial growth than in the stationary phase (Fig-1 and Fig-3). From Fig-1, the decline phase started at 14 hrs to 16 hrs of culture age and from Fig-3, the polysaccharide production was maximum between $14 \mathrm{hrs}$ to 16 hrs. Polysaccharide production and bacterial growth were directly proportional to each other (that is, polysaccharide production increased with culture age) until the stationary phase, but the polysaccharide concentration was found to have increased crossing the stationary phase until the early decline stage of growth.

Fig-4 shows the glucose feed supplementation rate affected bacterial growth significantly followed by capsular polysaccharide production. The polysaccharide production was maximum in the early decline phase of bacterial growth than the stationary phase. But the polysaccharide production was better in those batches (Experiments 2, 3, and 4) in which feeding strategy was maintained periodically. Fig-4 shows that the polysaccharide production increased about $45 \%-50 \%$ in maintained feeding strategy experiments.

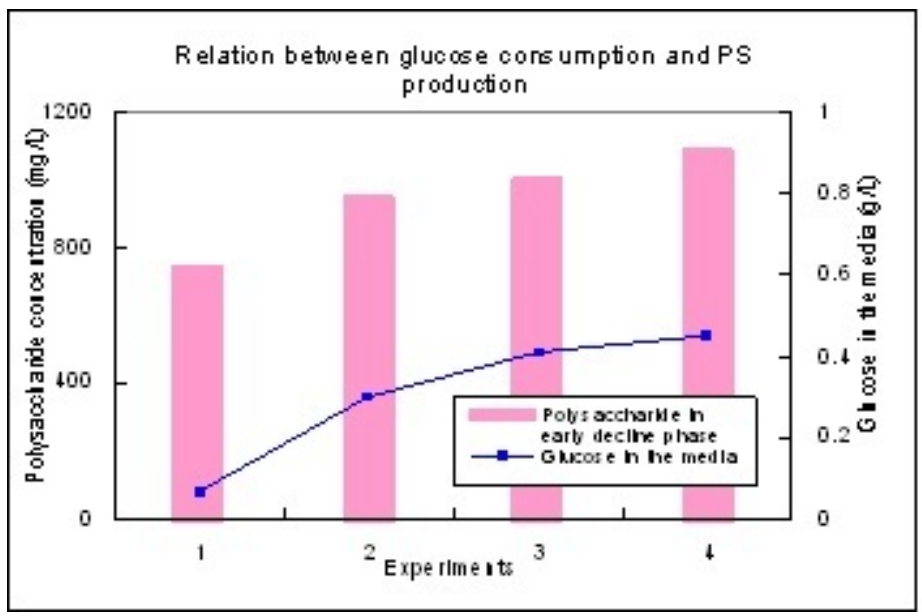

Figure 4: Polysaccharide production and respective glucose consumption in the early decline phase of Neisseria meningitidis $\mathrm{W}-135$ during fed-batch mode cultivation

Table-1a and Table-1b show the polysaccharide content, impurity present in the initial stage and final stage after purification. Table-1c shows the parameters specified by WHO (World Health Organization) for the final purified MenW-135 polysaccharide. The structural features of MenW polysaccharide produced was confirmed by NMR (Fig-5). The NMR spectra showed the presence of Neuraminic acid, Galactose, and O-acetylation.

Table - 1a

\begin{tabular}{|l|l|l|l|l|l|l|}
\hline \multicolumn{2}{|l|}{ Batch Size 2L } \\
\hline \multicolumn{2}{|l|}{ Sample stage } & $\begin{array}{l}\text { Harvest } \\
\text { age (hrs) }\end{array}$ & PS (mg/L) & $\begin{array}{l}\text { Total PS } \\
\text { mg (2L) }\end{array}$ & $\begin{array}{l}\text { Protein (\%) } \\
\text { *wrt PS }\end{array}$ & $\begin{array}{l}\text { Nucleic acid (\%) } \\
\text { *wrt PS }\end{array}$ \\
\hline \multirow{3}{*}{$\begin{array}{l}\text { Crude Harvest } \\
(100 k D T F F)\end{array}$} & Expt-1 & 18 & 550 & 1100 & 80 & 45 \\
\cline { 2 - 7 } & Expt-2 & 18 & 900 & 1800 & 80 & 51 \\
\cline { 2 - 7 } & Expt-3 & 18 & 950 & 1900 & 85 & 42 \\
\cline { 2 - 7 } & Expt-4 & 18 & 980 & 1960 & 92 & 41 \\
\hline
\end{tabular}

Table - 1b

\begin{tabular}{|l|l|l|l|l|l|l|}
\hline \multirow{2}{*}{ Sample stage } & $\begin{array}{l}\text { Protein \% } \\
\text { *wrt PS }^{*}\end{array}$ & $\begin{array}{l}\text { Nucleic } \\
\text { acid \% } \\
*_{\text {wrt PS }}\end{array}$ & $\begin{array}{l}\text { Sialic } \\
\text { content } \\
\text { of PS) }\end{array}$ & $\begin{array}{c}\text { acid } \\
(\mathbf{m g} / \mathbf{g}\end{array}$ & $\begin{array}{l}\text { O-acetyl } \\
\text { content } \\
\text { mol/g of PS) }\end{array}$ & $\begin{array}{l}\text { Endotoxin } \\
(\text { EU/ } \boldsymbol{\mu g} \text { of PS) }\end{array}$ \\
\hline \multirow{2}{*}{$\begin{array}{l}\text { Final } \\
\text { purified PS }\end{array}$} & Expt-1 & $<5$ & $<1$ & 600 & 1.2 & 65 \\
\cline { 2 - 7 } & Expt-2 & $<5$ & $<1$ & 686.94 & 1.54 & $<10$ \\
\cline { 2 - 7 } & Expt-3 & $<5$ & $<1$ & 628.35 & 1.36 & $<10$ \\
\cline { 2 - 7 } & Expt-4 & $<5$ & $<1$ & 667.34 & 1.38 & 64 \\
\hline
\end{tabular}

Table - 1c

\begin{tabular}{|c|c|c|c|c|c|}
\hline $\begin{array}{l}\text { WHO parameters } \\
\text { specifications for }\end{array}$ & Protein & $\begin{array}{l}\text { Nucleic } \\
\text { acid }\end{array}$ & $\begin{array}{l}\text { Sialic acid } \\
\text { content }\end{array}$ & $\begin{array}{l}\text { O-acetyl } \\
\text { content }\end{array}$ & $\begin{array}{l}\text { Endotoxin } \\
(\mathrm{EU} / \mu \mathrm{g})\end{array}$ \\
\hline $\begin{array}{l}\text { final purified MenW-135 } \\
\text { capsular polysaccharide }\end{array}$ & $<5 \%$ & $<1 \%$ & $\begin{array}{l}>560 \mathrm{mg} / \mathrm{g} \\
\text { of PS }\end{array}$ & $\begin{array}{l}>0.3 \mathrm{mmol} / \mathrm{g} \\
\text { of PS }\end{array}$ & $<100$ \\
\hline
\end{tabular}

Table-1a, Table-1b, Table-1c : Polysaccharide and impurity present in produced polysaccharide and parameter specifications as per WHO for MenW polysaccharide respectively. (*wrt - with respect to) 


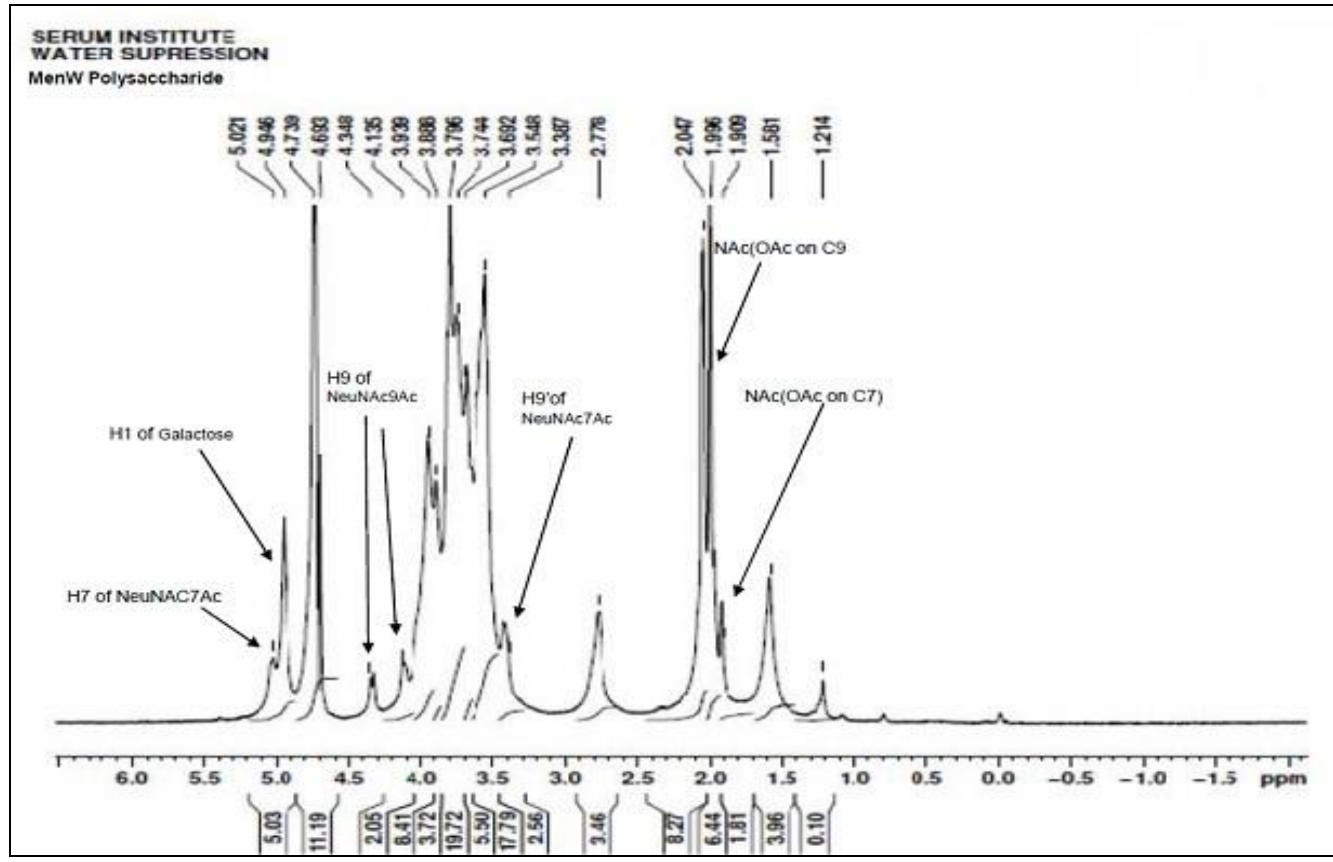

Figure 5: NMR spectroscopy of MenW135 polysaccharide

\subsection{Improved yield of MenW-135 polysaccharide}

\section{DISCUSSION}

The controlled fermentation parameters and feeding strategy resulted themselves in an improved bacterial growth that corresponds to a high yield of polysaccharide. Although Pengbo Ning et al previously showed a three-step submerged fermentation in which the polysaccharide yield was $55 \mu \mathrm{g} / \mathrm{mL}$ at $200 \mathrm{~L}$ scale [8]. Glucose and amino acid mixture are the major growth determining factors in the growth of Neisseria meningitidis W-135 along with other nutrient sources. Hence, we studied the 'feeding strategy' with and without maintaining the feed flow rate periodically in the fed-batch mode cultivation. We had studied four experimental batches of Neisseria meningitidis W-135, in which they were performed with different feed flow rates. $\mathrm{pH}$ control and continuous exponential feeding strategy maintained the cells in the stationary phase for a longer time hence increasing polysaccharide yield.

\subsection{Cultivation media and bacterial growth}

Fed-batch mode cultivation was adopted because it gives better bacterial growth and yield of polysaccharide levels than batch fermentation [16, 17] even though $\mathrm{pH}$ of the media need to be controlled [18]. The fermentation media, fermentation parameters, feed media, and feeding strategy are important bacterial growth determining factors in fed-batch cultivation. Neisseria meningitidis requires mineral salts, lactate, and amino acids (cysteine and glutamic acids). Lactate enhances the growth of Neisseria meningitidis in presence of glucose and lactate metabolizes rapidly than glucose [19], but our study with different carbon sources showed lactate had no significant effect on bacterial growth (data not shown). Presence of phospho transacetylase acetate kinase pathway was indicated by the formation of acetate metabolite in the course of fermentation [20, 21], which is responsible for $\mathrm{pH}$ change during fermentation [9]. In this study, $\mathrm{pH}$ was controlled by the addition of $0.25 \mathrm{M}$ alkali, which allowed the cells to survive for a longer time in the stationary phase and hence ensured better production of capsular polysaccharide.

US 7491517 disclosed a culture medium to grow Neisseria meningitidis that yielded $30-40 \mathrm{mg} / \mathrm{L}$ polysaccharide with the inclusion of $\mathrm{NH}_{4} \mathrm{Cl}$ along with the other components for MenW [22], whereas US 7399615 disclosed a fermentation media with the substitution of $\mathrm{NH}_{4} \mathrm{Cl}$ with soy peptone as nitrogen source, which yielded a polysaccharide concentration of $684 \mathrm{mg} / \mathrm{L}$ MenW in $2 \mathrm{~L}$ scale and $650 \mathrm{mg} / \mathrm{L}$ of polysaccharide in 400L scale with an OD about 10-11 [23]. It was observed that bacterial growth and polysaccharide production were greatly affected by high glucose concentration and amino acid mixture concentration in the media. The glucose consumption was directly proportional to feed flow rate. The study showed, in the stationary phase even though bacterial population was not multiplied, the glucose consumption occurred that indicated the consumed glucose must have been utilized for capsular polysaccharide production. One of our findings that the initial glucose concentration in the fermentation media is directly proportional to the polysaccharide production agrees with the previously reported study [16]. In this study, the concentration of polysaccharide in the media 
was estimated to be more in the stationary phase than in log phase but maximum in the early decline phase that supports the above mentioned hypothesis that glucose consumption in the stationary phase was utilized for the polysaccharide production.

Glucose present in the media is responsible for increase in NADP linked glutamate dehydrogenase $(\mathrm{GDH})$ level, which in turn enhances the bacterial growth by facilitating nitrogen metabolism [24]. Glutamic acid metabolism is a major factor that enhances the growth and virulence of Neisseria meningitidis by enhancing the citrate metabolism. [25-27]. N. meningitidis lacks a functional glutamate synthase gene, hence lacks glutamine synthase enzyme for the synthesis of glutamate [28]. The organism takes in glutamate either from the external environment or synthesized in NADPH specific glutamate dehydrogenase in presence of high external $\mathrm{NH}^{4+}$. We used sodium salt of glutamate at a concentration of 7-8\% in the feed media for better growth. The catalytic activity of glutamate in the catabolism of succinate, fumarate, and malate was previously shown by Weiss, [29] also glutamate serves to link nitrogen and carbon metabolism and helps to maintain acid stress [30].

Iron is an essential trace element for the production of proteins involved in numerous key metabolic processes including DNA replication, and hence electron transfer in the respiratory chain, metabolism of oxygen, peroxide, and superoxide [31] was supplemented in the initial stage in a minimum concentration as iron sulphate.

In Neisseria meningitidis, principal glucose metabolic pathway is through Entner-Doudoroff (ED) pathway and Pentose Phosphate (PP) pathway. Reported studies showed the major part of pyruvate (80\%) was synthesized through ED pathway and PP pathway corresponding to $20 \%$ of the metabolism. The activity of Embden-Meyerhof-Parnas (EMP) pathway in the metabolism has not been observed that indicates that phosphofructokinase gene is missing in Neisseria meningitidis [9, 32]. A NMR and enzyme study of carbon catabolism of Neisseria meningitidis showed the presence of all the citric acid cycle enzymes in the cell extracts grown on glucose and pyruvate, whereas the specific activities for most of the enzymes were significantly higher (3-5 fold) in glucose grown cells, in which the pyruvate dehydrogenase activity was more than 10 folds higher in glucose grown cells that supported our hypothesis that glucose is one of the major growth determining factors [33]. A study on metabolite production in the cultivation of Neisseria meningitidis $\mathrm{C}$ reported that the bacterial growth depends on acetic acid formation, whereas lactic acid metabolite production was not associated with biomass growth, on which a survey revealed that the utilization of carbon source by Neisseria meningitidis may be through different metabolic pathways depending on the cultivation conditions [34]. Cysteine, which is a major source of sulfur and hence essential for growth of $N$. meningitides, was fed about a concentration of $0.04 \%$. Cysteine is converted to glutathione (GSH), then to glutathione sulfide by oxidation, hence controls the cellular $\mathrm{H}_{2} \mathrm{O}_{2}$ level $[35,36]$. Transcriptome analysis suggested that cysteine depletion impairs sulfur supply for Fe-S protein assembly and cause oxidative stress [37].

In this study, glucose along with nitrogen sources and other nutrients supported bacterial growth in the initial phase, in which maintained glucose feeding played a significant role in better cultivation of Neisseria meningitidis W-135 followed by enhanced capsular polysaccharide production. Also, this study showed the polysaccharide production was maximum in the early decline phase than in the stationary phase.

\subsection{Characterization of MenW polysaccharide}

The structural features of MenW polysaccharide produced were confirmed by NMR, which were similar to previously reported structure [5].

V. Conclusion
Thus our experiment has proved a significant contribution to the fed-batch mode cultivation of Neisseria meningitidis W-135 that reveals the significance of maintained flow rate of glucose feed (as carbon source) in combination with nitrogen sources (soya and amino acids) on bacterial growth for better production of capsular polysaccharide. It was concluded from the study that even though maximum glucose consumption was in the stationary phase, polysaccharide production was maximum at the early decline phase of bacterial growth. The outcome of this study could be extrapolated for the large scale cultivation of Neisseria meningitidis $\mathrm{W}-135$ by fed-batch mode fermentation. The enhanced capsular polysaccharide production can help in faster development of efficient and cost effective vaccine against Neisseria meningitidis W-135.

\section{REFERENCES}

[1]. Koumaré, B., Ouedraogo-Traoré, R., Sanou, I., Yada, A.A., Sow, I., Lusamba, P.S.,...\& Kaboré, A.B. (2007). The First Large Epidemic of Meningococcal Disease Caused by Serogroup W135, Burkina Faso, 2002. Vaccine, 25 Suppl. 1, A37-A41.

[2]. Storz, C., Schutz, C., Tluway, A., Matuja, W., Schmutzhard, E., \& Winkler, A.S. (2016). Clinical findings and management of patients with meningitis with an emphasis on Haemophilusinfluenzae meningitis in rural Tanzania. Journal of the Neurological Sciences, 366 , 52-8.

[3]. Claus, H., Borrow, R., Achtman, M., Morelli, G., Kantelberg, C., Longworth, E.,...\& Vogel, U. (2004). Genetics of capsule O- acetylation in serogroup C, W- 135 and Y meningococci. Molecular Microbiology, 51(1), 227-239.

[4]. Willis, L.M. \& Whitfield, C. (2013). Structure, biosynthesis, and function of bacterial capsular polysaccharides synthesized by ABC 
transporter-dependent pathways. Carbohydrate Research, 378, 35-44.

[5]. Wang, C.H., Li, S.T., Lin, T.L., Cheng, Y.Y., Sun, T.H., Wang, J.T.,...\& Wu, C.Y. (2013). Synthesis of Neisseria meningitidis serogroup W135 capsular oligosaccharides for immunogenicity comparison and vaccine development. Angewandte Chemie International Edition, 52(35), 9157-9161.

[6]. Moore, S.L., Uitz, C., Ling, C.C., Bundle, D.R., Fusco, P.C., \& Michon, F. (2007). Epitope specificities of the group Y and W-135 polysaccharides of Neisseria meningitidis. Clinical and Vaccine Immunology, 14(10), 1311-1317.

[7]. Lingappa, J.R., Al-Rabeah, A.M., Hajjeh, R., Mustafa, T., Fatani, A., Al-Bassam, T.,...\& Al-Jeffri, M. (2003). Serogroup W-135 meningococcal disease during the Hajj, 2000. Emerging Infectious Diseases, 9(6), 665-671.

[8]. Ning, P., Zhang, Y., Liu, P., Xu, X., Gong, C., Huang, C., \& Bai, J. (2012). Process Optimisation for Increased Polysaccharide Yield of Neisseria Meningitidis (Serogroup W135) by Submerged Fermentation. Biotechnology \& Biotechnological Equipment, 26(5), 32243230.

[9]. Baruque-Ramos, J., Hiss, H., Vicentin, M.A., Paz, M.F.D., Peixoto, A., Leal, M.B.B.,...\& Raw, I. (2001). Nitrogen consumption during batch cultivation of Neisseria meningitidis (serogroup C) in Frantz medium. Brazilian Journal of Microbiology, 32(4), 305-310.

[10]. Paz, M.F.D., Baruque-Ramos, J., Hiss, H., Vicentin, M.A., Leal, M.B.B., \& Raw, I. (2003). Polysaccharide production in batch process of Neisseria meningitidis serogroup C comparing Frantz, modified Frantz and Cartlin 6 cultivation media. Brazilian Journal of Microbiology, 34(1), 27-32.

[11]. Harrison, L.H. (2010). Epidemiological profile of meningococcal disease in the United States. Clinical Infectious Diseases, 50 (Supplement 2), S37-S44.

[12]. Reddy, J.R. (2009). Method of producing meningococcal meningitis vaccine for Neisseria meningitidis serotypes A, C, Y, and W-135. U.S. Patent 7,491,517.

[13]. Svennerholm, L. (1957). Quantitive estimation of sialic acids: II. A colorimetric resorcinol-hydrochloric acid method. Biochimica et Biophysica Acta, 24, 604-611

[14]. Lowry, O.H., Rosebrough, N.J., Farr, A.L., \& Randall, R.J. (1951). Protein measurement with the Folin phenol reagent. The Journal of Biological Chemistry, 193(1), 265-275.

[15]. Hestrin, S. (1949). The reaction of acetylcholine and other carboxylic acid derivatives with hydroxylamine, and its analytical application. Journal of Biological Chemistry, 180(1), 249-261.

[16]. Henriques, A.W.S., Jessouroun, E., Lima, E.L., \& Alves, T.L.M. (2005). Mathematical modeling of capsular polysaccharide production by Neisseria meningitidis serogroup C in bioreactors. Brazilian Journal of Chemical Engineering, 22(4), 585-592.

[17]. Zhan, X., Zhu, L., Wu, J., Zhen, Z., \& Jia, W. (2002). Production of polysialic acid from fed-batch fermentation with pH control. Biochemical Engineering Journal, 11(2), 201-204.

[18]. 18. Egen, R., Fortin, L., Sun, W.W., Egen, R.C., Ann, F.L., \& Sun, W.W.Q. (2003). Feed comprises glucose, amino acids, and trace metal elements; for production of vaccines. U.S. Patent Application 10/439,878.

[19]. 19. Catlin, B.W. (1973). Nutritional profiles of Neisseria gonorrhoeae, Neisseria meningitidis, and Neisseria lactamica in chemically defined media and the use of growth requirements for gonococcal typing. Journal of Infectious Diseases, 128(2), 178-194.

[20]. Exley, R.M., Shaw, J., Mowe, E., Sun, Y.H., West, N.P., Williamson, M.,...\& Tang, C.M. (2005). Available carbon source influences the resistance of Neisseria meningitidis against complement. The Journal of Experimental Medicine, 201(10), 1637-1645.

[21]. Baart, G.J., Langenhof, M., van de Waterbeemd, B., Hamstra, H.J., Zomer, B., van der Pol, L.A.,...\& Martens, D.E. (2010). Expression of phosphofructokinase in Neisseria meningitidis. Microbiology, 156(2), 530-542.

[22]. Reddy, J.R. (2009). Method of producing meningococcal meningitis vaccine for Neisseria meningitidis serotypes A, C, Y, and W-135. U.S. Patent 7,491,517.

[23]. Egen, R.C., Fortin, L.A., \& Sun, W.W.Q., Egen Richard C. (2008). Animal component free meningococcal polysaccharide fermentation and seedbank development. U.S. Patent 7,399,615.

[24]. Pagliarulo, C., Salvatore, P., De Vitis, L.R., Colicchio, R., Monaco, C., Tredici, M.,...\& Alifano, P. (2004). Regulation and differential expression of gdhA encoding NADP- specific glutamate dehydrogenase in Neisseria meningitidis clinical isolates. Molecular Microbiology, 51(6), 1757-1772.

[25]. Archibald, F.S. \& DeVoe, I.W. (1978). Iron in Neisseria meningitidis: minimum requirements, effects of limitation, and characteristics of uptake. Journal of Bacteriology, 136(1), 35-48.

[26]. Hill, J.C. (1971). Effect of glutamate on exogenous citrate catabolism of Neisseria meningitidis and of other species of Neisseria. Journal of Bacteriology, 106(3), 819-823.

[27]. Colicchio, R., Ricci, S., Lamberti, F., Pagliarulo, C., Pagliuca, C., Braione, V.,...\& Cintorino, M. (2009). The meningococcal ABCtype L-glutamate transporter GltT is necessary for the development of experimental meningitis in mice. Infection and Immunity, 77(9), 3578-3587.

[28]. Talà, A., Monaco, C., Nagorska, K., Exley, R.M., Corbett, A., Zychlinsky, A.,...\& Tang, C.M. (2011). Glutamate utilization promotes meningococcal survival in vivo through avoidance of the neutrophil oxidative burst. Molecular Microbiology, 81(5), 1330-1342.

[29]. Weiss, E. (1970). Catabolic activities of Neisseria meningitidis: utilization of succinate. Journal of Bacteriology, 101(1), 133-137.

[30]. Feehily, C. \& Karatzas, K.A.G. (2013). Role of glutamate metabolism in bacterial responses towards acid and other stresses. Journal of Applied Microbiology, 114(1), 11-24.

[31]. Rusniok, C., Vallenet, D., Floquet, S., Ewles, H., Mouzé-Soulama, C., Brown, D.,...\& Pelicic, V. (2009). NeMeSys: a biological resource for narrowing the gap between sequence and function in the human pathogen Neisseria meningitidis. Genome Biology, 10(10), R110.

[32]. Baart, G.J., Zomer, B., de Haan, A., van der Pol, L.A., Beuvery, E.C., Tramper, J., \& Martens, D.E. (2007). Modeling Neisseria meningitidis metabolism: from genome to metabolic fluxes. Genome Biology, 8(7), R136.

[33]. Leighton, M.P., Kelly, D.J., Williamson, M.P., \& Shaw, J.G., 2001. An NMR and enzyme study of the carbon metabolism of Neisseria meningitidis. Microbiology, 147(6), 1473-1482.

[34]. Baruque-Ramos, J., Hiss, H., Converti, A., Goncalves, V.M., \& Raw, I. (2006). Accumulation of organic acids in cultivations of Neisseria meningitidis C. Journal of Industrial Microbiology and Biotechnology, 33(10), 869-877.

[35]. Seib, K.L., Tseng, H.J., McEwan, A.G., Apicella, M.A., \& Jennings, M.P. (2004). Defenses against oxidative stress in Neisseria gonorrhoeae and Neisseria meningitidis: distinctive systems for different lifestyles. Journal of Infectious Diseases, 190(1), $136-147$.

[36]. Rusniok, C., Vallenet, D., Floquet, S., Ewles, H., Mouzé-Soulama, C., Brown, D.,...\& Pelicic, V. (2009). NeMeSys: a biological resource for narrowing the gap between sequence and function in the human pathogen Neisseria meningitidis. Genome Biology, 10(10), R110.

[37]. van de Waterbeemd, B., Zomer, G., van den IJssel, J., van Keulen, L., Eppink, M.H., van der Ley, P., \& van der Pol, L.A. (2013). Cysteine depletion causes oxidative stress and triggers outer membrane vesicle release by Neisseria meningitidis; implications for vaccine development. PloS one, 8(1), e54314. 